\title{
Polychlorinated Biphenyl-Induced Alteration of Biologic Parameters in the Rat ${ }^{1,2}$
}

\author{
J. V. Bruckner, K. L. Khanna AND H. H. Cornish \\ The University of Michigan, Department of Environmental \& Industrial Health, \\ School of Public Health, Ann Arbor, Michigan 48104 \\ Received May 8, 1973; accepted September 1, 1973
}

Polychlorinated Biphenyl-Induced Alteration of Biologic Parameters in the Rat. Bruckner, J. V., KhanNa, K. L. AND Cornish, H. H. (1974). Toxicol. Appl. Pharmacol. 28, 189-199, Aroclor 1242, a commercial polychlorinated biphenyl (PCB) mixture, was administered ip to rats for 10 weeks. Principal findings included: loss of body weight; hepatic and renal damage, with some animals exhibiting renal papillary epithelial hyperplasia; slight reduction in erythrocyte count, diameter, and hemoglobin content, with an elevation in serum iron; diminished plasma corticosteroid and glucose concentrations; increased urinary excretion of protein, sugars, and coproporphyrin.

The effect of PCBs on several hepatic microsomal enzymatic parameters was also evaluated. Maximal hydroxylation and $N$-demethylation activities were observed 3-10 days following a single ip injection $(100 \mathrm{mg} / \mathrm{kg})$. Each remained significantly higher than control values after 20 days, with hydroxylation activity still $150 \%$ of controls after 40 days. The minimal effective single dose for induction of hydroxylation activity was approximately $5 \mathrm{mg} / \mathrm{kg}$. Induction of hydroxylation activity was found to be dose-dependent; however, a smaller degree of correlation was noted between $\mathrm{N}$-demethylation activity and dose. Valucs for cytochromes $\mathrm{P}_{450}$ and $b_{5}$ and NADPH-cytochrome $c$ reductase activity were observed to roughly parallel hydroxylation and $\mathrm{N}$-demethylation activities, the highest degree of correlation was manifest between enzymatic activity and cytochrome $P_{450}$ values.

Commercial polychlorinated biphenyl (PCB) products consist of mixtures of PCB isomers, differing from one another in extent of chlorination. Although their use has recently been voluntarily restricted in the United States to closed-system heat transfer applications, global environmental contamination and accumulation in food chains has been demonstrated (Risebrough and deLappe, 1972). Humans have been exposed to PCBs, either via accidental contamination of foodstuffs by quantities large enough to elicit toxic symptoms (Kuratsune et al., 1972), or via PCB residues in everyday foods. The latter mode of exposure has apparently resulted in deposition of detectable concentrations ( $\geqslant 1 \mathrm{ppm}$ wet weight) of PCBs in human adipose tissue within the general population of the United States (Price and Welch, 1972). York.

${ }^{1}$ Presented at the 1973 Meeting of the Society of Toxicology, March 18-22, 1973, New York, New

${ }^{2}$ This investigation was supported in part by research grant GM 15269, Institute of General Medical Sciences, training grant 5T01-ES00138, Institute of Environmental Health Sciences, U. S. Public Health Service.

Copyright 1974 by Academic Press, Inc. 
Despite a number of recent investigations, toxic manifestations of PCB exposure in mammals are not well understood. Some of the major findings to date include: renal and/or hepatic injury in mice and monkeys (Nishizumi, 1970), rabbits (Vos and Beems, 1971), and rats (Kimbrough et al., 1972; Bruckner et al., 1973); porphyria in rabbits (Vos and Notenboom-Ram, 1972); hepatic microsomal enzyme induction in rats (Fujita et al., 1971; Litterst et al., 1972; Bruckner et al., 1973); alteration of steroid metabolism in boars (Platonow et al., 1972) and lipid metabolic alteration in rats (Nagai et al., 1971).

In order to gain better insight into the toxic nature of $\mathrm{PCBs}$, a representative commercial product (Aroclor 1242) was administered to rats. Emphasis was placed upon effects on hepatic and renal function, hematologic parameters, hepatic microsomal enzyme stimulation, porphyria induction, and steroid metabolism.

\section{METHODS}

Male, Sprague-Dawley rats ${ }^{3}$ were used in both subacute and hepatic microsomal enzyme induction studies. The animals were housed in stainless steel cages in air-conditioned quarters, with Rockland rat and mouse chow and tap water available ad libitum.

Subacute study. The subacute dosage regimen consisted of ip injections (100 $\mathrm{mg}$ Aroclor $1242^{4} / \mathrm{kg}$ ) given twice weekly for 6 weeks, then weekly thereafter for 4 weeks to a group of 9 rats. Each rat therefore received a total dose of $1.6 \mathrm{~g} / \mathrm{kg}$. Dilutions of Aroclor 1242 were made with peanut oil to an average injection volume of $0.4 \mathrm{ml}$. A control group of 4 rats was given an equivalent volume of peanut oil by ip injection.

Histopathology. Tissue samples of liver, kidney, spleen and adrenal from rats in the subacute investigation were processed and stained with hematoxylin and eosin. Liver and kidney specimens were also stained for lipid with Sudan IV.

Hematology. Hematologic examinations were performed by standard techniques. Total blood hemoglobin concentrations were measured by a standard technique involving cyanmethemoglobin formation (Davidsohn and Henry, 1969). Mean corpuscular hemoglobin concentration (MCHC) was computed by dividing hemoglobin concentration in $\mathrm{g} / 100 \mathrm{ml}$ by hematocrit in percent. Blood urea nitrogen (BUN) concentrations were determined with a Nesslerization technique (Frankel and Reitman, 1963).

Serum iron and bilirubin concentrations were measured by standard procedures (Frankel and Reitman, 1963), as were blood glucose values (Mark and Zimmer, 1967). The technique of Solem and Brinck-Johnsen (1965) was utilized for analysis of plasma corticosteroids.

Urinalysis. Urinary sugars and proteins were estimated by established procedures (Davidsohn and Henry, 1969). Twenty-four-hour excretion of coproporphyrin (Schwartz et al., 1951) and of 17-ketosteroids (Mark and Zimmer, 1967) was also determined.

Microsomal enzyme induction studies. Rats weighing 250-300 g were housed in groups of 2 or 3 animals per cage for dose-response and time-effect studies. Dilutions of Aroclor 1242 were made with peanut oil to an average injection volume of $0.15 \mathrm{ml}$. Controls received $0.15 \mathrm{ml}$ peanut oil by ip injection. Rats were divided into 6 groups of 4 rats each

${ }^{3}$ Spartan Research Farm, Lansing, Michigan.

${ }^{4}$ Lot No. KA-419. Kindly supplied by Monsanto Chemical Company, St. Louis, Missouri. 
for the dose-response study, with each group receiving 100, 50, 25, 5, 1, or $0 \mathrm{mg}$ Aroclor $1242 / \mathrm{kg}$ as a single ip injection. Animals were sacrificed $72 \mathrm{hr}$ after dosing. For the timeeffect study, a single ip injection of $100 \mathrm{mg}$ Aroclor $1242 / \mathrm{kg}$ was given to each of 5 groups of rats (6 PCB-treated and 3 controls per group). A group of rats was sacrificed at intervals of $1,5,10,20$ and 40 days post injection.

Microsomal assays. Hepatic microsomal hydroxylation activity was quantitated by measurement of $N$-acetyl-p-aminophenol formation from acetanilide, $N$-demethylation activity by measurement of 4-aminoantipyrine formation from aminopyrine. Activity of each was calculated in terms of $\mu \mathrm{g}$ product formed $/ \mathrm{mg}$ microsomal protein $/ 20 \mathrm{~min}$. Procedures used were described in a previous study (Bruckner et al., 1973), as were methods for the determination of cytochromes $\mathbf{P}_{450}$ and $b_{5}$. Each cytochrome concentration was expressed as $\mathrm{nmol} / \mathrm{mg}$ microsomal protein. Determination of NADPHcytochrome $c$ reductase activity was performed according to the technique of Baron and Tephly (1969), and expressed as nmol cytochrome $c$ reduced/mg microsomal protein: min. Microsomal protein concentrations were determined by the biuret method (Robinson and Hogden, 1940).

Statistical analysis. All results were analyzed by Student's $t$ test. Correlation coefficients $(r)$ were computed to examine relationships between certain microsomal parameters.

\section{RESULTS}

\section{Subacute Study}

The effect of the subacute dosage regimen on body weight is illustrated in Fig. 1. A marked reduction in mean body weight gain of PCB-treated rats became evident after 5 weeks of twice weekly injections of $100 \mathrm{mg}$ Aroclor $1242 / \mathrm{kg}$.

Histopathologic alterations were evident only in the liver and kidneys of rats which received Aroclor 1242 over the 10 -week period. Sudanophilic vacuolation was present in

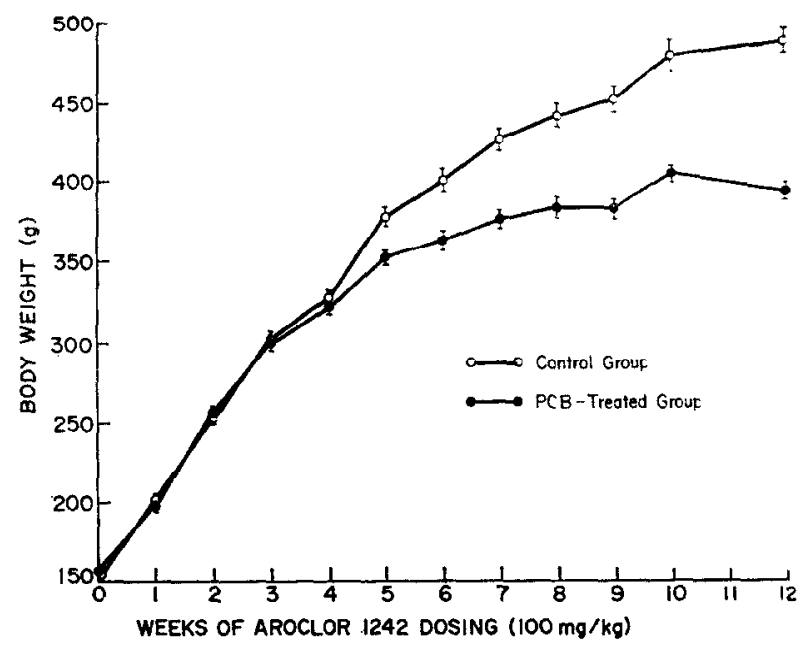

Fig. 1. Body weight gain of rats dosed with Aroclor $1242(100 \mathrm{mg} / \mathrm{kg}$ ip $)$ twice weekly for 6 weeks, then once weekly for 4 weeks thereafter. Plots represent mean values \pm SE of the control group ( 4 rats) and of the PCB-treated group (9 rats). 
midzonal areas of each hepatic lobule, leaving relatively unaffected cells in centrolobular and in portal zones. Multiple, tiny vacuoles were distributed uniformly through the cytoplasm of affected hepatocytes. Widely scattered, necrotic foci were also present in the liver of each PCB-dosed animal.

Kidneys of Aroclor 1242-dosed rats exhibited a moderate degree of dilation of proximal convoluted and collecting tubules, often with proteinaceous casts. Diffuse areas of sudanophilic vacuolation were evident within renal epithelium of proximal convoluted tubules. A unique finding in the present study was a marked dilation and degeneration of collecting tubules at the tip of the renal papilla of some PCB-dosed rats. The papillary capsular epithelium in such instances showed extensive vacuolation and hyperplasia (Figs. 2 and 3).

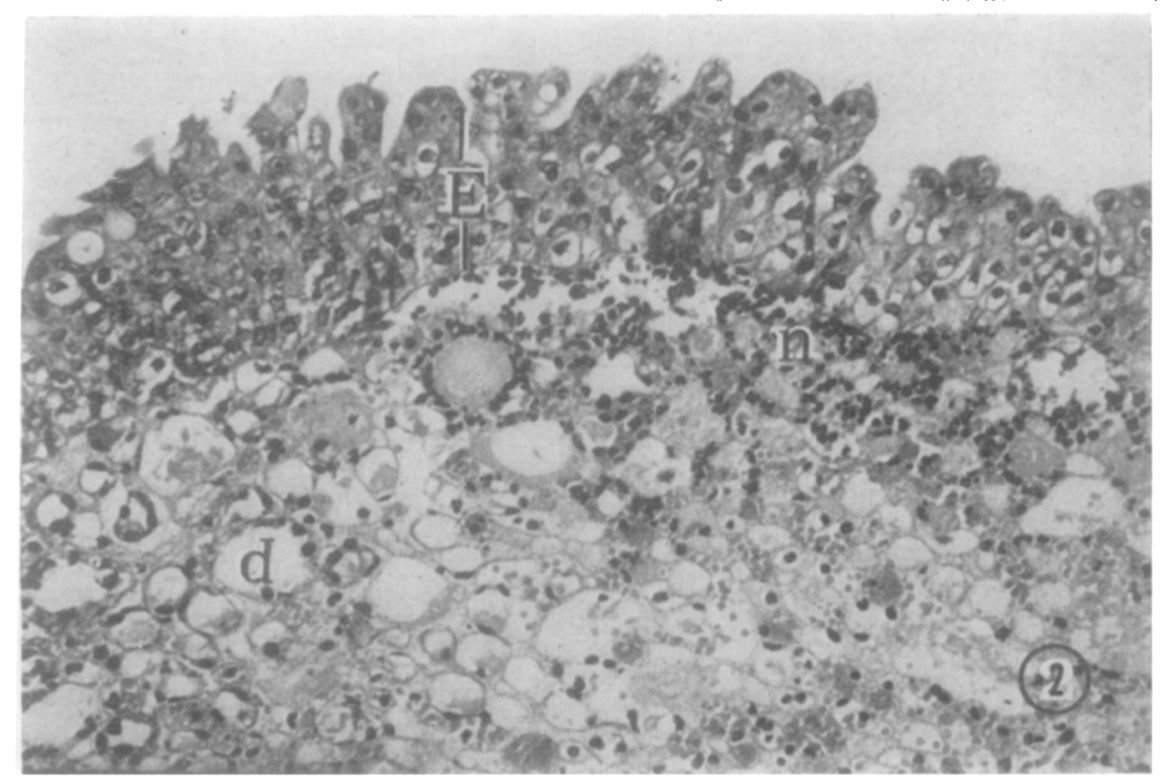

FIG. 2. Renal papilla of a rat maintained on the subacute dosage regimen. The hyperplastic epithelium (E) overlies a damaged area containing both necrotic (n) and dilated (d) collecting tubules. Hematoxylin and eosin. $\times 170$.

Hematologic findings are shown in Table 1. Hematocrit, erythrocyte count, erythrocyte diameter, $\mathrm{MCHC}$, and hemoglobin concentration were found to be somewhat lower in PCB-dosed animals than in controls. An elevation in the leucocyte count was noted in the blood of PCB-dosed rats, with a large increase in the proportion of circulating neutrophils. Erythrocytic anisocytosis was evident in PCB-treated rats when compared to controls, though no reticulocytosis or other morphologic abnormalities were evident. Osmotic fragility tests revealed that these erythrocytes were no more resistant to lysis in hypotonic saline than those from control rats.

Additional hematologic findings are presented in Table 2. Serum iron of PCB-dosed rats was found to be elevated when compared to control values. BUN and serum bilirubin values, though, were almost identical in both groups. Plasma corticosteroid and glucose concentrations were both diminished by Aroclor 1242 administration. Food 

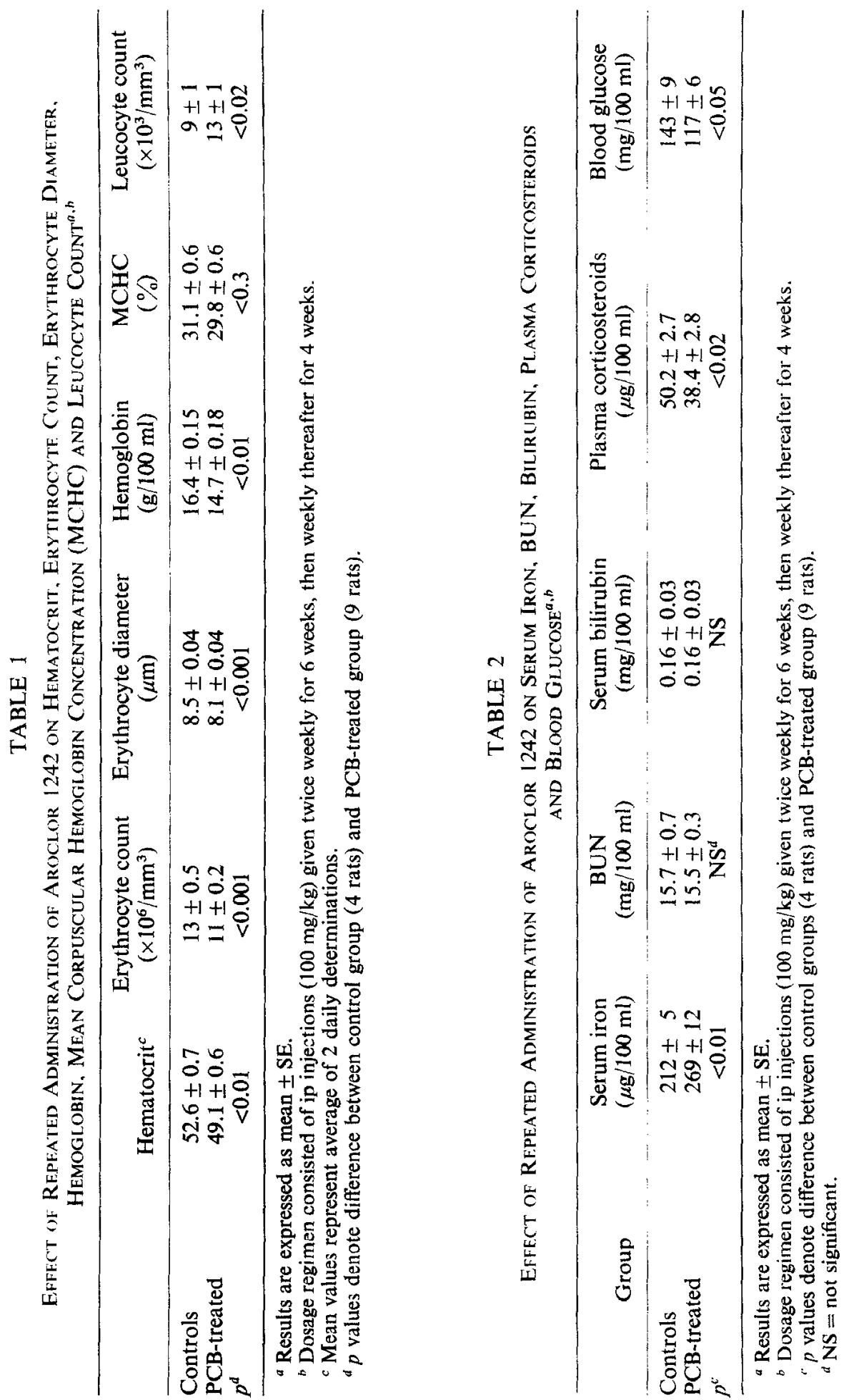


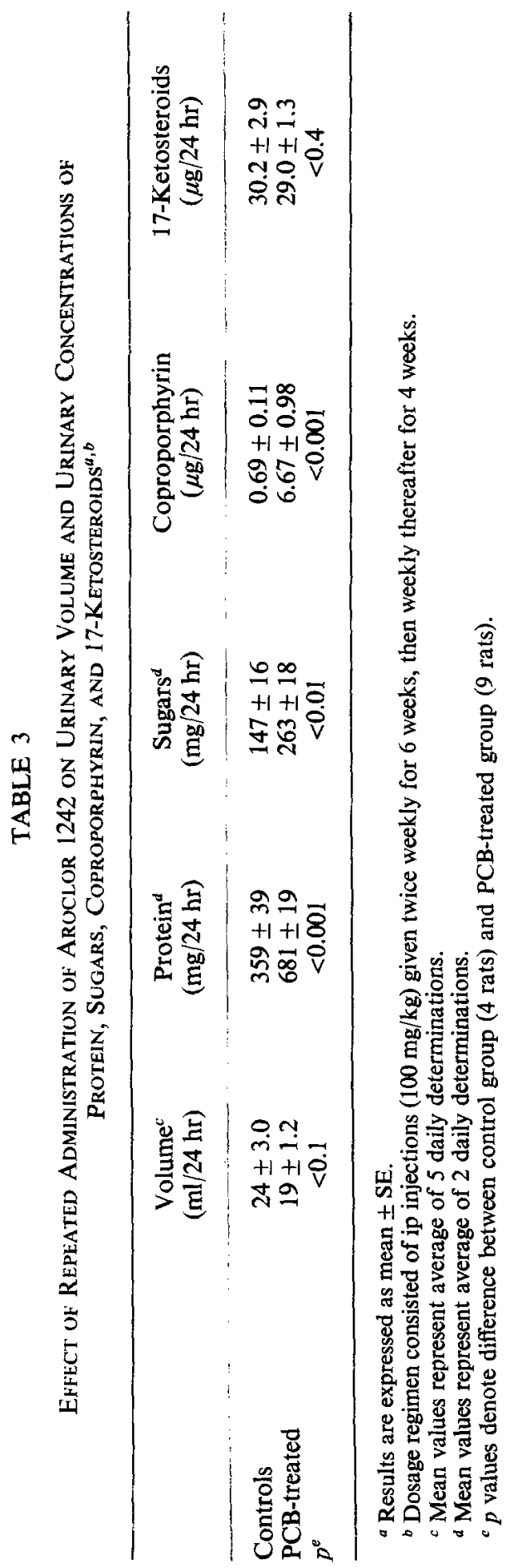


was not withheld prior to blood collection, in an effort to avoid stress-induced alteration of blood glucose and plasma steroid concentrations.

Results of urinalyses are given in Table 3 . A reduction in the mean daily urine output of Aroclor 1242-dosed rats was measured, but variability was such that the $p$ value was slightly more than 0.05 . Mean urinary protein and sugar values of both control and PCB-treated groups were relatively high. This phenomenon was probably the result of the collection procedure, in which voided urine may have been contaminated by fecal and food materials. Still, the Aroclor 1242-dosed rats exhibited elevated urinary protein and sugar concentrations. Coproporphyrin excretion was markedly higher in PCBtreated animals; however, 17-ketosteroid excretion was equivalent in each group.

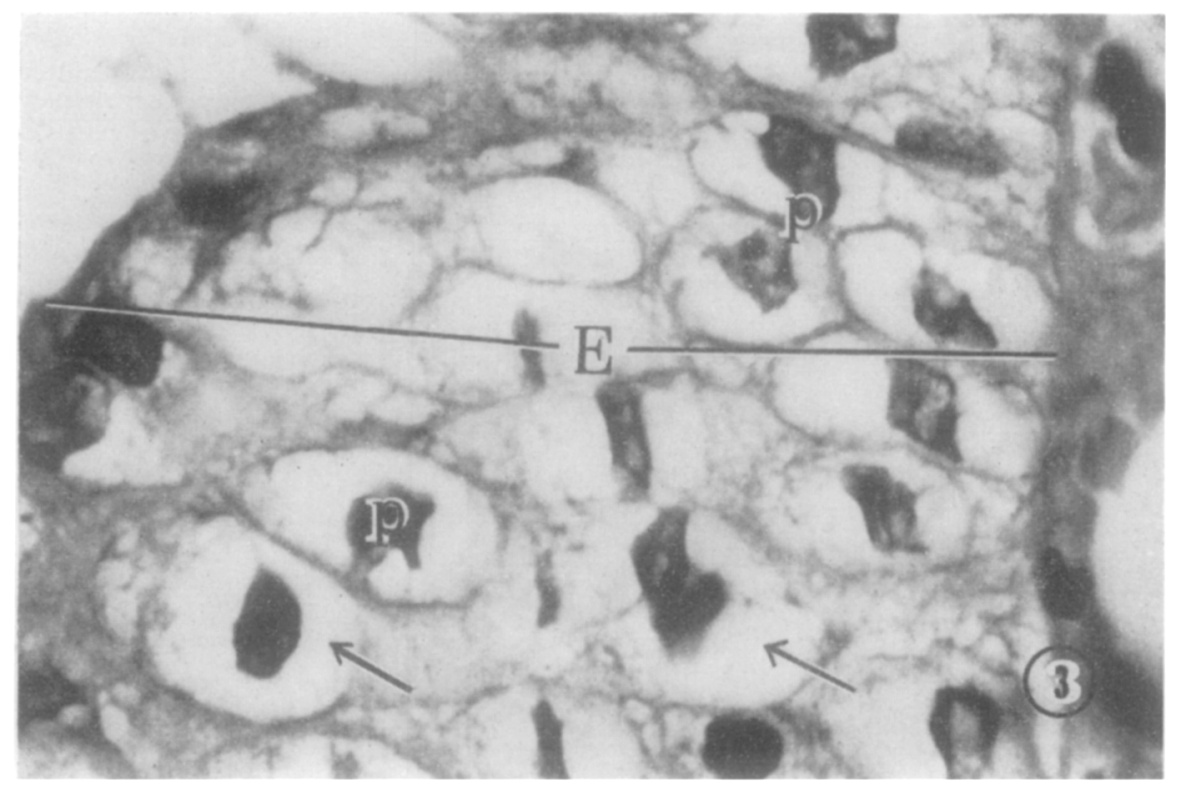

FIG. 3. Higher magnification of papillary epithelium (E) pictured in Fig. 2. Observe the severe cytoplasmic vacuolation (arrows) and the pyknosis (p). Hematoxylin and eosin. $\times 1100$.

\section{Microsomal Studies}

The effects of a single ip injection of $100 \mathrm{mg}$ Aroclor $1242 / \mathrm{kg}$ on microsomal enzymatic parameters are illustrated in Fig. 4. Hydroxylation and N-demethylation activities were significantly $(p<0.025)$ elevated $24 \mathrm{hr}$ after dosing. Although each appeared maximal after 5 days, neither 5-day value was significantly $(p<0.05)$ different from its respective 3- or 10-day values. Hydroxylation activity showed the most marked rise, reaching a value almost $500 \%$ of controls. Both remained significantly $(p<0.05)$ higher than controls after 20 days, though $\mathrm{N}$-demethylation activity was equivalent to control values after 40 days. Hydroxylation activity remained approximately $150 \%$ of control values 40 days following the single injection. Cytochromes $\mathrm{P}_{450}$ and $b_{5}$ and NADPHcytochrome $c$ reductase activity all showed significant $(p<0.05)$ increases 3 days after dosing. Each remained elevated over controls at 20 days post injection, but returned to control values after 40 days. 


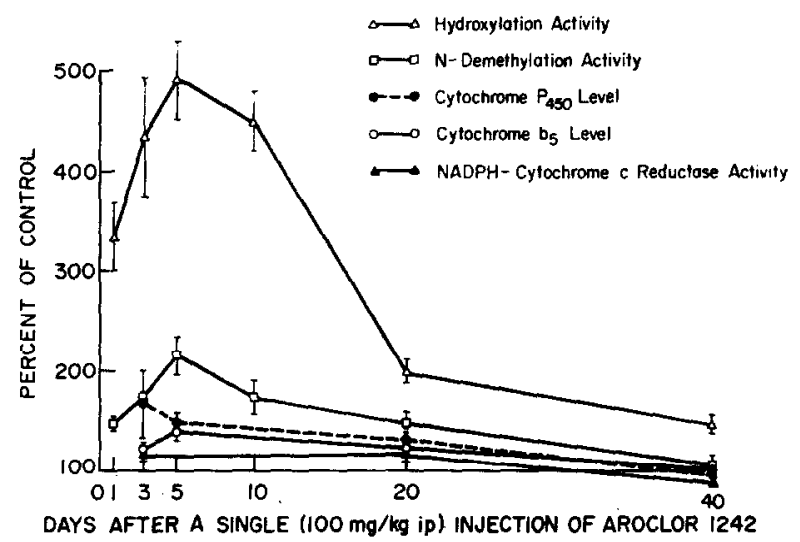

FIG. 4. Effect of a single dose of Aroclor $1242(100 \mathrm{mg} / \mathrm{kg}$ ip) on hepatic microsomal enzymatic parameters. Each point represents the mean value of 6 PCB-treated rats vs that of 3 control rats: vertical bars represent the $\mathrm{SE}$.

Dose-response relationships of the selected enzymatic parameters are shown in Fig. 5. No elevation of any parameter was noted in response to a single $1 \mathrm{mg} / \mathrm{kg}$ dose. Hydroxylation activity showed a small increase in response to $5 \mathrm{mg} / \mathrm{kg}$, though individual variability created a rather large SE. Significant $(p<0.01)$ increases in both hydroxylation and in $\mathrm{N}$-demethylation activity were measured in response to 25,50 , and 100 $\mathrm{mg} / \mathrm{kg}$ doses of Aroclor 1242. Although hydroxylation activity was dose-dependent $(r=0.98, p<0.01$ ), a smaller degree of correlation between dose and $\mathrm{N}$-demethylation activity $(r=0.72, p<0.2)$ was manifest. Cytochromes $\mathrm{P}_{450}$ and $b_{5}$ and NADPHcytochrome $c$ reductase activity exhibited initial increases over controls in rats receiving $50 \mathrm{mg} / \mathrm{kg}$. Cytochrome $P_{450}$ values were even greater in rats dosed with $100 \mathrm{mg} / \mathrm{kg}$; however, cytochrome $b_{5}$ and NADPH-cytochrome $c$ reductase activity remained equivalent to their respective $50 \mathrm{mg} / \mathrm{kg}$ values.

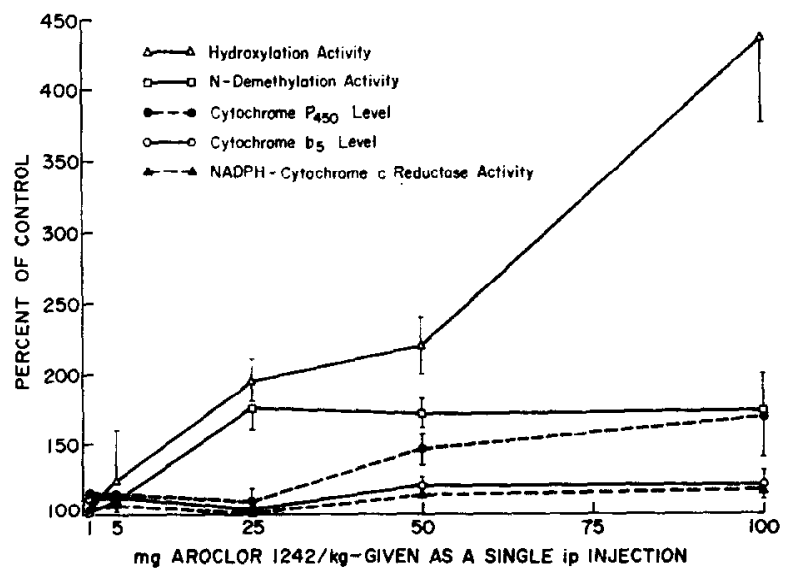

FIG. 5. Dose-response relationships of hepatic microsomal enzymatic parameters, measured $72 \mathrm{hr}$ after a single injection $(100 \mathrm{mg} / \mathrm{kg}$ ip) of Aroclor 1242. Each point represents the mean value of 4 PCBtreated rats vs that of 4 control rats; vertical bars represent the SE. 


\section{DISCUSSION}

Our finding of reduction in body weight gain after 4-5 weeks of administration of Aroclor 1242 concurs with reports of other investigators (Nagai et al., 1971; Vos and Notenboom-Ram, 1972), Although modes and regimens of administration of PCB compounds and isomers varied in these reports, adverse effects on body weight gain were noted within 4-6 weeks of initiation of dosing.

Pathologic alterations in the liver and kidneys of subacutely dosed rats were quite similar to those observed in an earlier subacute study (Bruckner et al., 1973). Hepatic vacuolation was also noted by Koller and Zinkl (1973) to precede midzonal necrosis. Renal papillary degeneration and epithelial alterations, however, were unique to the present study. Visual observation of urine of Aroclor 1242-dosed rats revealed an abnormally dark coloration, as well as a reduction in urine volume. Renal injury was further evidenced by the demonstration of glycosuria and proteinuria. As blood glucose values of these animals were lower than those of controls, it may be assumed that glycosuria did not result from exceeding the resorptive threshold of the renal epithelium. Rather, the loss of glucose via the urine may have contributed to the depressed blood glucose concentration. The presence of proteinuria suggested glomerular damage: however, light microscopic examination revealed no apparent structural anomalies.

Aroclor 1242-induced increases in hydroxylation and in $\mathrm{N}$-demethylation activities appeared maximal from 3-10 days after the single injection of Aroclor $1242 . \mathrm{N}$ demethylation activity returned to normal 40 days after a single injection (100 $\mathrm{mg}$ Aroclor $1242 / \mathrm{kg}$ ip), although hydroxylation activity remained $150 \%$ of the control value. Similar peak activity times and prolonged induction periods for hepatic microsomal O-demethylase (Benthe et al., 1972) and aniline hydroxylase (Fujita et al., 1971) activities have been elicited in rats by a single dose of PCBs. Such prolonged elevation of microsomal enzyme activity indicates that PCBs may alter the rate of metabolism of a variety of substances for extended periods of time.

The minimal effective dose of Aroclor 1242 for induction of hydroxylation activity was approximately $5 \mathrm{mg} / \mathrm{kg}$ in this 10 -week study, however, individual variation produced a value of $p$ greater than 0.05 . Although hydroxylase activity appeared dosedependent, 50 and $100 \mathrm{mg} / \mathrm{kg}$ doses produced no more an inductive effect of $\mathrm{N}$-demethylase activity than did $25 \mathrm{mg} / \mathrm{kg}$. Dose-related increases in hydroxylase, demethylase, and nitroreductase activities in rat liver microsomes have been reported (Litterst et al.. 1972) in response to a 4-week feeding regimen.

Microsomal values for cytochrome $\mathbf{P}_{450}$, cytochrome $b_{5}$, and NADPH-cytochrome $c$ reductase activity tended to parallel microsomal enzymatic activity. However, marked differences were evident between the magnitude of these 3 cytochrome parameters and that of corresponding enzymatic activity. Greim and Remmer (1966) reported a similar phenomenon in rats in response to DDT. In the present study the $\mathrm{P}_{450}$ concentration was the most reliable index of hydroxylase activity $r=0.67, p<0.001$ with NADPH-cytochrome $c$ reductase activity $(r=0.46, p<0.01)$ and the $b_{5}$ value $(r=0.20, p<0.2)$ less reliable indices. Some correlation of $\mathrm{N}$-demethylase activity with $\mathrm{P}_{450}(r=0.65$, $p<0.001), b_{5}(r=0.60, p<0.001)$, and NADPH-cytochrome $c$ reductase activity $(r=0.36, p<0.02)$ was demonstrable. It appears unlikely that induction of microsomal enzyme activity resulted from a selective stimulation of any one of these cytochrome 
parameters. Rather, the level of each was likely elevated in response to enhanced activity of the entire microsomal oxidative sequence.

The administration of many drugs and insecticides has been shown to be associated, in hepatic microsomes, with stimulation of drug and steroid hydroxylation, proliferation of smooth endoplasmic reticulum, increased cytochrome $\mathrm{P}_{450}$, and diminished bioeffects of drugs and steroids (Gillette et al., 1969). Plasma adrenocorticosteroid concentrations of Aroclor 1242-dosed rats in our own study were lower than controls, suggesting a PCB-mediated increase in corticosteroid metabolism and excretion. Concomitant blood glucose values of PCB-treated rats were also lower than controls. This latter finding may have resulted from diminished plasma adrenocorticosteroids and/or loss of glucose in the urine via damaged renal epithelium. In contrast, Aroclor 1242 appeared to have no effect on urinary excretion of 17-ketosteroids.

Studies have demonstrated a number of diverse compounds to elicit concurrent induction of microsomal enzyme activity and porphyria (Wada et al., 1968; Baron and Tephly, 1970). Our own results confirmed that Aroclor 1242 produced microsomal enzyme induction and porphyria, the latter evidenced by marked rises in urinary coproporphyrin excretion.

Hematologic effects of Aroclor 1242 included slight decreases in hematocrit, erythrocyte count and diameter, and hemoglobin concentration. A decreased incorporation of iron into protoporphyrin was suggested by the elevation of serum iron and decrease in hemoglobin concentration.

Contribution by Aroclor 1242 to the mild reduction in erythrocyte count via a hemolytic action was discounted by the finding of identical bilirubin values in serum of PCBdosed and that of control rats. No alteration in osmotic fragility was observed, since erythrocytes from PCB-dosed rats were no more resistant to lysis in hypotonic saline than those from control rats.

The findings of renal and hepatic damage, hematologic effects, porphyria, altered plasma glucose and corticosteroid concentrations, and hepatic microsomal enzyme induction for extended periods of time indicate that PCBs affect a wide variety of biologic parameters. The long-term elevation of microsomal enzyme activity after a single dose of PCBs also suggests that these compounds have a great potential for interaction with the biologic responses of mammals to other chemical and environmental stresses.

\section{REFERENCES}

Baron, J. AND TePhly, T. R. (1969). Effect of 3-amino-1,2,4-triazole on the stimulation of hepatic microsomal heme synthesis and induction of hepatic microsomal oxidases produced by phenobarbital. Mol. Pharmacol. 5, 10-20.

Baron, J. AND TePhly, T. R. (1970). Further studies on the relationship of the stimulatory effects of phenobarbital and 3,4-benzpyrene on hepatic heme synthesis to their effects on hepatic microsomal drug oxidations. Arch. Biochem. Biophys. 139, 410-420.

BeNTHE, H. F., Schmoldt, A. AND SCHMIdT, H. (1972). Induktion mikrosomaler Leberenzyme nach einmaliger Gabe von polychlorierten Biphenylen (PCB) und anschliessbender StressSituation. Arch. Toxicol. 29, 97-106.

BruCKNer, J. V., KhanNa, K. L. And Cornish, H. H. (1973). Biological responses of the rat to polychlorinated biphenyls. Toxicol. Appl. Pharmacol. 24, 434-448.

Davidsohn, I. AND Henry, J. B. (1969). Clinical Diagnosis by Laboratory Methods, 14th ed., pp. 48, 61, 130-133. Saunders, Philadelphia, Pennsylvania. 
Frankel, S. And Reitman, S. (1963). Clinical Laboratory Methods and Diagnosis, 6th ed.. pp. 59-60, 97-99, 226-227. Mosby, St. Louis, Missouri.

Fujita, S., Tsuji, H., Kato, K., Saeki, S. AND Tsukamoto, H. (1971). Effect of biphenyl chlorides on rat liver microsomes. Fukuoka Acta Med. 62, 30-34.

Gillette, J. R., Conney, A. H., Cosmides, G. J., Estabrook, R. W., Fouts, J. R. ANd Mannering, G. J., eds. (1969). Microsomes and Drug Oxidations, 1st ed. Academic Press. New York, New York.

Greim, H. AND Remmer, H. (1966). Die Wirkung von DDT und Phenobarbital auf microsomale hydroxylierende Cytochrome. Arch. Exp. Pathol. 255, 16-17.

Kimbrough, R. D., Linder, R. E. AND Gaines, T. B. (1972). Morphological changes in livers of rats fed polychlorinated biphenyls. Arch. Environ. Health 25, 354-364.

Koller, L. D. AND ZinkL, J. G. (1973). Pathology of polychlorinated biphenyls in rabbits. Amer. J. Pathol. 70, 363-378.

Kuratsune, M., Yoshimura, T., Matsuzaka, J. and Yamaguchi, A. (1972). Epidemiologic study on Yusho, a poisoning caused by ingestion of rice oil contaminated with a commercial brand of polychlorinated biphenyls. Environ. Health Perspect. 1, 119-128.

LitTerst, C. L., FARBer, T. M., BAKER, A. M. AND VAN LOON, E. J. (1972). Effect of polychlorinated biphenyls on hepatic microsomal enzymes in the rat. Toxicol. Appl. Pharmacol. 23. $112-122$.

MARK, D. D. ANd Zimmer, A. (1967). Atlas of Clinical Laboratory Procedures, 1st ed., Vol. 1. pp. 69-73, 94-100. McGraw-Hill, New York.

Nagai, J., Furukawa, M., Yae, Y. And Higuchi, K. (1971). The influence of chlorobiphenyls (Kanechlor) administration on the organ lipids of rats. Fukuoka Acta Med. 62, 42-47.

NishizUmi, M. (1970). Light and electron microscope study of chlorobiphenyl poisoning. Arch. Environ. Health 21, 620-632.

Platonow, N. S., LiptraP, K. M. AND Geissinger, H. D. (1972). The distribution and excretion of polychlorinated biphenyls (Aroclor 1254) and their effect on urinary gonadal steroid levels in the boar. Bull. Environ. Contam. Toxicol. 7, 358-365.

PRICE, H. A. AND WELCH, R. L. (1972). Occurrence of polychlorinated biphenyls in humans. Environ. Health Perspect. 1, 73-78.

RiseBROUGH, R. W. AND DELAPPE, B. (1972). Accumulation of polychlorinated biphenyls in ecosystems. Environ. Health Perspect. 1, 39-45.

Robinson, H. W. AND Hogden, C. G. (1940). The biuret reaction in the determination of serum proteins. 1. A study of the conditions necessary for the production of a stable color which bears a quantitative relationship to the protein concentration. J. Biol. Chem. 135, 707-725.

Schwartz, S., Zieve, L. ANd Watson, C. J. (1951). An improved method for the determination of urinary coproporphyrin and an evaluation of factors influencing the analysis. J. Lab. Clin. Med. 37, 843-859.

SOLEM, J. H. AND BRINCK-JoHnsEN, T. (1965). An evaluation of a method for determination of free corticosteroids in minute quantities of mouse plasma. Scand.J. Clin. Lab. Invest.. Suppl. $80,1-14$.

Vos, J. G. AND Beems, R. B. (1971). Dermal toxicity studies of technical polychlorinated biphenyls and fractions thereof in rabbits. Toxicol. Appl. Pharmacol. 19, 617-633.

Vos, J. G. And Notenboom-Ram, E. (1972). Comparative toxicity study of $2,4,5,2^{\prime}, 4^{\prime}, 5^{\prime}$ hexachlorobiphenyl and a polychlorinated biphenyl mixture in rabbits. Toxicol. t $\mathrm{ppl}$. Pharmacol. 23, 563-578.

WADA, O., YANO, Y., URATA, G. AND NAKAO, K. (1968). Behavior of hepatic microsomal cytochromes after treatment of mice with drugs known to disturb porphyrin metabolism in liver. Biochem. Pharmacol. 17, 595-603. 